\title{
Effect of Body Movements in the Venous Blood Flow and Lymphatic Circulation
}

\author{
Eduardo Pinto-Ferreira ${ }^{1^{*}}$ \\ ${ }^{1}$ Instituto Portugues de Oncologia Francisco Gentil, Portugal \\ *Corresponding author: Eduardo Pinto-Ferreira: epintoferreira@gmail.com
}

Citation: Pinto-Ferreira E. (2021) Effect of Body Movements in the Venous Blood Flow and Lymphatic Circulation. Open Science Journal 6(2)

Received: $4^{\text {th }}$ December 2020

Accepted: 23rd April 2021

Published: $9^{\text {th }}$ June 2021

Copyright: (c) 2021 This is an open access article under the terms of the $\underline{\text { Creative Commons Attribution }}$ License, which permits unrestricted use, distribution, and reproduction in any medium, provided the original author and source are credited.

Funding: The author(s) received no specific funding for this work

Competing Interests: The author has declared that no competing interests exists.

\section{Abstract:}

Balistocardiography studies the movements of the human body resulting from the sudden ejection of blood in the great vessels at each heartbeat. The main objective of this work is to demonstrate the opposite, the effect of the movements of the human body on venous return and lymphatic flow. The secondary objective is to draw attention to the study of the oscillatory movements of the body, or just the legs, to promote venous and lymphatic return. These effects follow Sir Isaac Newton laws. With the body movement, the one-way valve structure of these vessels will cause a mobilization of venous blood and lymph to the proximal side A constructed model attempted to mimic a segment of vein with its valve, and to evaluate the effectiveness of oscillatory movements in the progression of liquid, to demonstrate the effect of oscillatory movement on a flow of liquid in a unidirectional valve system. There was an elevation of the liquid with a difference in level that varied from $9 \mathrm{~cm}$ to $34 \mathrm{~cm}$, depending on the amplitude and frequency. In a preliminary study, to assess the effect of oscillatory movements on leg swelling, this movements was applied in a clinical cases. There was regression of the oedema, by oscillatory movements, that was correlated with increase in lymphatic and venous drainage. Venous stasis is a predisposing factor of venous thromboembolism. The oscillatory movements of the legs improving venous circulation may contribute to the prophylaxis of venous thromboembolism. In conclusion, it is of interest to study its application in some situations of venous thromboembolism risk.

Keywords: Body movements, Venous blood flow, Lymphatic circulation, Newton's law 


\section{Introduction}

"Ballistocardiography is a technique for producing a graphical representation of repetitive motions of the human body arising from the sudden ejection of blood into the great vessels with each heart beat" [1]. The author studied it in 1964 for his licentiateship thesis [2]. The primary objective of this work is to demonstrate the opposite, the effect of movements of the human body on the venous return and lymphatic flow.

Venous stasis is a predisposing factor of venous thromboembolism (VTE), [3].

The secondary objective is to draw attention to the study of the oscillatory movements of the body, or just the legs, to promote venous and lymphatic return.

\section{Application of Newton' laws to the motions of the Lower Limbs}

The effect of oscillatory movements of the leg, supported on tiptoe, on the venous blood flow, can be explained by the general behaviour of the contact forces between two bodies. These laws were described for Sir Isaac Newton and published in 1687, in his work Philosophiae Naturalis Principia Mathematica [4].

According to Newton's 2nd law, whenever a non-zero resultant of forces acts on the blood mass, this mass is submitted to an acceleration that is inversely proportional to its mass. In this context, the upward movements of the legs produces an upward venous blood mass momentum ensured by the inter-valvular venous blood, as the valves close at its distal end. This upward blood mass movement will remain when the legs start the downward movement. This is explained by Newton's first law of inertia, which provides the rationale for the inability of the venous blood mass of to change its state of motion (or rest). The upward flow of blood facilitates the opening of the valves on proximal and distal side. In addition, the downward movement of the leg causes an upward movement of the blood (already moving upward by the law of inertia). This is based on the law of conservation of centre of gravity $[5,6]$ stating that two masses can not, by mutual action, shift their common centre of gravity and on the Newton's 3rd law, or law of action and reaction, proving that every action provokes a reaction of equal intensity in the same direction and opposite.

In the superficial veins of the upper limbs, the valve distribution is comparable to that observed in the lower limbs [7]. Thousands of small valves were identified in the venous microcirculation in various regions of the body [8]. All this valve structure under the action of oscillatory movements of the body will have an effect of proximal mobilization of the venous blood flow, similar to many thousands of mini and micro pumps in the peripheral venous circulation.

In the system of lymphatic vessels, with one-way valves structure as in the veins, adding to the various forces driving the lymph flow [9], the oscillatory motion will enhance lymphatic drainage as well under the same effects of Sir Isaac Newton' laws 


\section{Material and methods}

I - Experimental demonstration: Effect of oscillatory motion in the flow of a liquid in a one-way valve system.

It was built a model (Figure1) that seeks to mimic a segment of vein with its valve to demonstrate the effect of oscillatory motion in a liquid flow in a system of one-way valve.

The system consists of the following elements:

- a chamber, formed by a set of segments of transparent plastic pipe, as sketched in Figure 1, containing inside a thin small rubber tube which simulates the venous valve;

- a tube at the distal end connected to a water tank;

- a tube at the proximal end, which connects to another placed vertically to read the water level and assess the difference in relation to the water level in the tank at the distal end.

- the tubes of the distal and proximal ends have the same calibre.

The piping system that forms the one-way valve is mounted on a moving base capable of producing oscillatory motion. The movement of a connecting rod and crank enables this oscillatory motion, with the possibility of varying the frequency of the crank rotation, and the amplitude with the length of his arm. The movement with a controlled uniform speed is ensured by a precision bushing drill with variable speed switch. The experiment is conducted by recording the water level in the rest position, as well as the level reached during oscillatory movements, at different oscillatory frequencies and amplitudes.

The experiment was carry out to a frequency of 120, 140, 160 and 180 movements per minute for a crank arm with $15 \mathrm{~mm}$, giving an amplitude of 30 $\mathrm{mm}$, to a frequencies of 100, 120, 140 and 160 for the crank arm with $20 \mathrm{~mm}$ and an amplitude of $40 \mathrm{~mm}$, and frequencies of 80, 100, 120 and 140 for the crank arm with $25 \mathrm{~mm}$ and an amplitude of $50 \mathrm{~mm}$. It was registered the average of ten readings performed for each set of amplitude and frequency

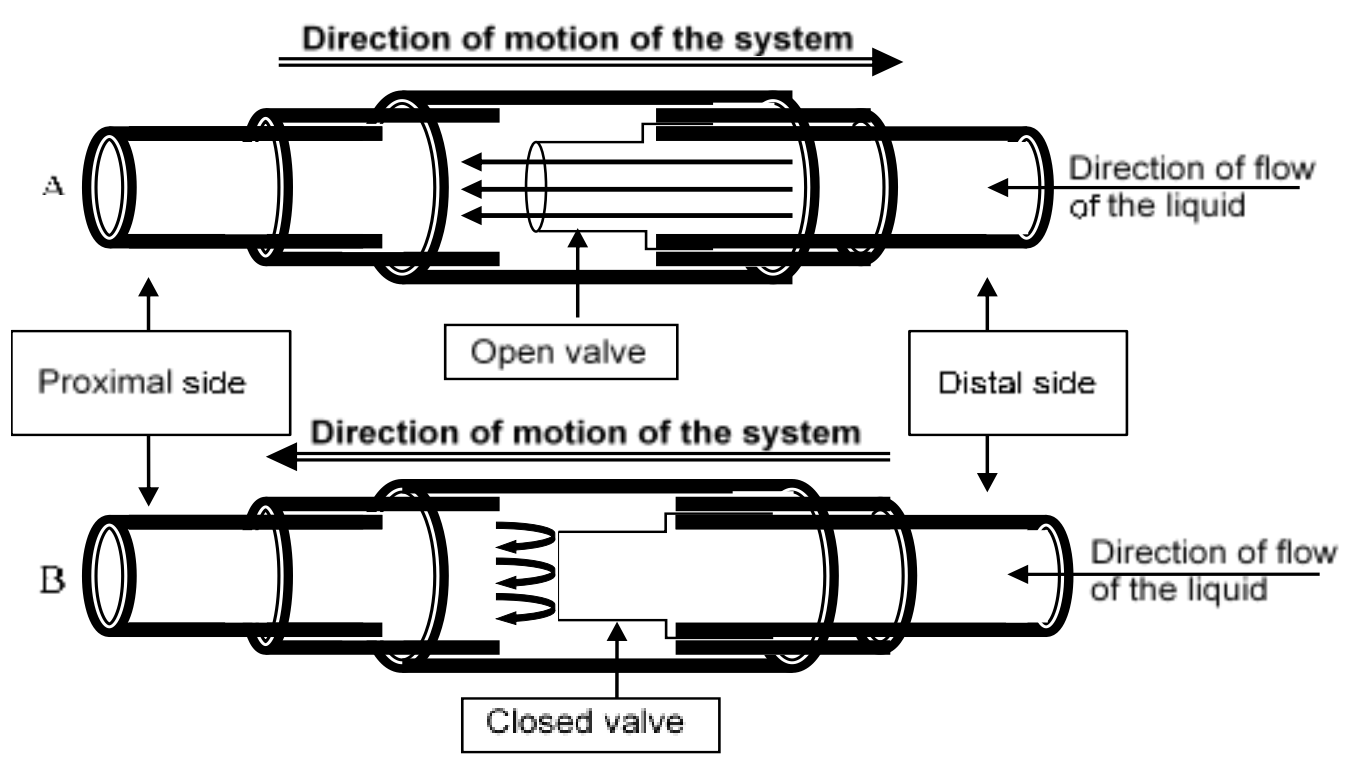

Figure 1 - A - The movement of the system to distal side opens the valve inside rubber tube, with progression of the liquid to the proximal side, B - the motion of the system to proximal side closes the valve inside rubber tube, producing a force that accelerates the liquid in the proximal direction. 
II - Case study: Effect of oscillatory motion on flow of the lymphatic system and venous circulation

To evaluate the effect of oscillatory motion in the oedema on the legs, this movement was applied, as a preliminary study, to only one clinical case:

Individual male, 77 years old, with leg oedema after sitting more than 2 hours.

A circumferential marker line was applied on the right leg, to a level of $10 \mathrm{~cm}$ above the medial of the malleolus. The patient was kept seated with the legs at rest over 2 hours and after, with the leg in horizontal position, the circunferente measurements were taken using a MyoTape Body. Tape Measure device encircled just under the marker line. To evaluate leg oedema, [10 - 12] the circumference was measured before and after each test, calculating the area for each reading and the difference between areas to each trial.

- $\quad$ 1st trial - After measure of leg circumference, were held oscillatory movements of the right leg supported on tiptoe, for 5 minutes, at a frequency of 140 oscillations per minute, followed by new circumference evaluation;

- 2nd trial -In other day with the patient lying in a supine position, after assess the perimeter on the same leg, these was elevated and maintained at rest for 5 minutes with a 60 degree angle to the horizontal and thereafter was calculated the leg circumference;

- Newton effect trial - to eliminate the effect of muscle contraction, the leg oscillation took place passively for 5 minutes, at the same frequency of 140 oscillations per minute, with leg circumference assessment before and after test.

\section{Results}

I - Effect of oscillatory motion in a system with one-way valve

The values shown in Table 1 and Figure 2 represent the average of ten readings taken for each set amplitude / frequency.

Table 1 - Value of the difference in level of liquid related with the amplitude and frequency of oscillatory movements

Frequency (oscillations per minute)

\begin{tabular}{c|c|c|c|c|c|c} 
Amplitude & 80 & 100 & 120 & 140 & 160 & 180 \\
\hline $30 \mathrm{~mm}$ & & & $11 \mathrm{~cm}$ & $18 \mathrm{~cm}$ & $23 \mathrm{~cm}$ & $32 \mathrm{~cm}$ \\
\hline $40 \mathrm{~mm}$ & & $9 \mathrm{~cm}$ & $23 \mathrm{~cm}$ & $29 \mathrm{~cm}$ & $34 \mathrm{~cm}$ & \\
\hline $50 \mathrm{~mm}$ & $9 \mathrm{~cm}$ & $15 \mathrm{~cm}$ & $24 \mathrm{~cm}$ & $34 \mathrm{~cm}$ & & \\
\hline
\end{tabular}




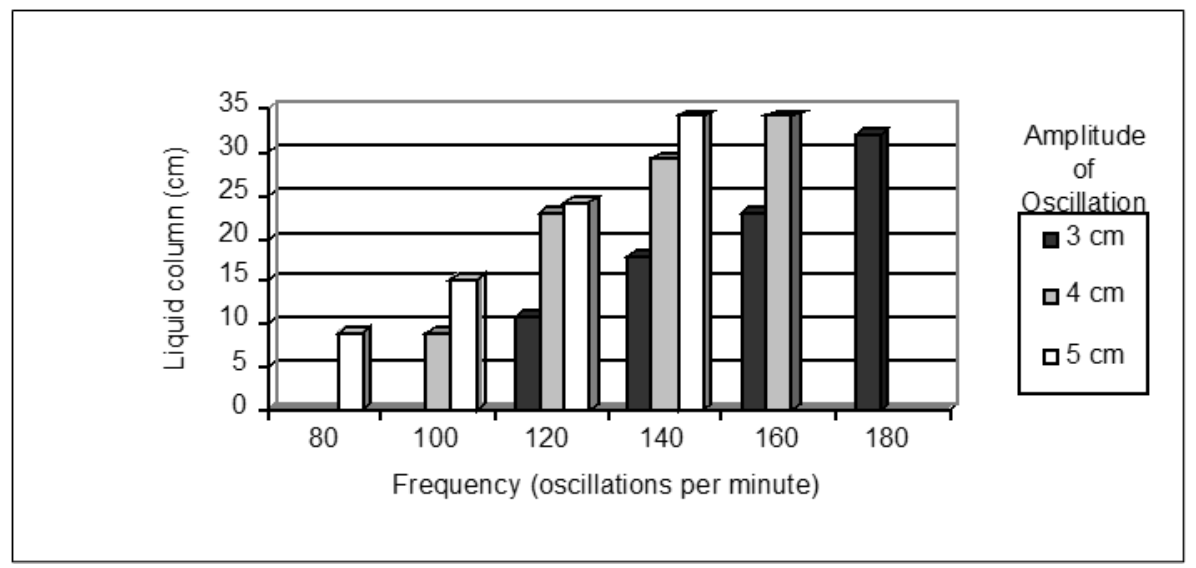

Figure 2 - The columns represent different levels of liquid related with amplitude and frequency of oscillatory movements.

II - Effect of oscillatory motions on oedema and areas of the leg.

The values shown in Table 2 compare the effect of active oscillatory motions in the first experiment, with hydrostatic effect on leg on upward position in the second test and with passive oscillatory motion on Newton effect trial.

Table 2 - Results to the three trials and the difference between areas before and after each test.

\begin{tabular}{l|c|c|c}
\multicolumn{1}{c|}{ Trials } & $\begin{array}{c}\text { Areas } \\
\text { before trial }\end{array}$ & $\begin{array}{c}\text { Areas } \\
\text { after trial }\end{array}$ & $\begin{array}{c}\text { Difference between } \\
\text { areas }\end{array}$ \\
\hline 1st trial & $45,836 \mathrm{~cm} 2$ & $44,326 \mathrm{~cm} 2$ & $1,516 \mathrm{~cm} 2$ \\
\hline 2nd trial & $43,943 \mathrm{~cm} 2$ & $42,083 \mathrm{~cm} 2$ & $1,860 \mathrm{~cm} 2$ \\
\hline Newton effect & $43,799 \mathrm{~cm} 2$ & $42,456 \mathrm{~cm} 2$ & $1,343 \mathrm{~cm} 2$ \\
\hline
\end{tabular}

1st trial - there was regression of the area documented on the result.

2nd trial - The regression of the area was a little more than on the first trial.

Newton effect trial - the effect was smaller than that observed on the first trial.

\section{Discussion}

I - Effect of oscillatory motion in a system with one-way valve

In the experimental model, the slope of the water reflects the effectiveness of oscillatory movements in the progression of the liquid, in a one-way valve system, in accordance with the amplitude and frequency.

With the start of movement of the system on a proximal direction it was observed a slight valve reflux, especially in the lower frequencies, and a retreat of small thin rubber tube, especially in higher frequencies. These facts can cause a slight loss of efficiency, so the values presented in Table 1 give us a conservative estimate.

Since the model seeks to mimic the action of a segment of vein with the valve, these results can be extrapolated to the venous circulation.

The distribution of venous valves occurs, usually, at intervals of $13 \mathrm{~cm}$, limiting capillary pressure below $10 \mathrm{mmHg}$ [7]. Thus, taking into account the liquid displacement observed in the experimental research, the blood mass movement under the effect of oscillatory motions, can go beyond the next valve. 
II - Effect of oscillatory motion on the oedema and area of the leg.

The regression of the oedema and area on the leg underwent oscillatory movements, was near to the effect achieved on the member at an upward position. In the Newton effect test, this regression was smaller, however, this effect was only due to oscillatory movements, in the absence of muscle activity. They showed the effectiveness of oscillatory motions to increase lymphatic and venous drainage.

The result of this experiment, limited to just one patient, serves only to draw attention to its effect, justifying a study with a larger sample.

This effect of lower limb movements on the venous and lymphatic circulations can occur during walking or running, and cycling. These activities, with horizontal and vertical combined movements, will influence the venous and lymphatic return, with greater or lesser degree, at the level of each set of venous or lymphatic segment with its attached valve. The action of the resultant force is directly proportional to the cosine of the angle that the direction of this force makes with the orientation of each segment of vessel. The effectiveness of the movement also depends on the frequency and amplitude of these exercises. The movements of the arms will produce a similar effect on the venous and lymphatic streams. In any physical activity, beyond the effect of muscular work, this physics laws explain the influence of body movements on the two circulatory systems.

This concept can help us in interpreting the results of other studies, as well as research into new treatment guidelines. So, concerning the venous valve cycle the Fedor Lurie's study [13] states that "participants performed foot movements repeatedly, the duration of the equilibrium phase and closed phase reflected the frequency of movements". The Newton's laws also influenced these phases of the venous valve cycle. The oscillatory movements of the legs supported on tiptoe can be studied to prevent orthostatic hypotension, common in the elderly, as a simple and no pharmacologic strategy to counteracting orthostatic volume shift. [14]. The Newton's laws can justify the stabilization of the blood circulation and the syncope prevention that took place throughout the passive cycle and stepping movements of the legs during head-up tilt testing. [15] Also it can help to explain the diminution in calf volume in the human lower legs, during walking and running, observed by C. Stick, H. Jaeger and E. Witzleb. [16] Also, the continuum of care for patients in cases of prolonged immobilization and risk for hypo-coagulant therapy or post-thrombotic syndrome [17] may be useful a bed with lengthwise oscillatory motions, after study the best amplitude and frequency to these oscillatory movements. The improvement of venous and lymphatic drainage under these oscillatory movements, like observed with massages [18, 19], leads us to think that a mechanical device with these effects may be in the near future, a physiotherapy equipment. Also, to study whether a device with oscillatory movements is more effective and comfortable in reducing arm oedema volume, in women treated on breast cancer, than a manual lymphatic drainage or a simple lymphatic drainage [20]. 


\section{Conclusion}

This research shows us, how the movement of the human body can influence the behaviour of the venous and lymphatic circulation. This is, indeed, the most important conclusion.

How the oscillatory movements of the legs improve venous flow, it is of interest to study its application in prophylaxis of VTE risk, in situations such as long journeys with little mobility. So, to all persons travelling on air flights, the oscillatory movements of the legs can help to avoid the venous stasis, caused by prolonged sitting in a limited space.

\section{Acknowledgment}

I dedicate this work to my wife, our children, and their Families. In memory of Professor Manuel Gonçalves Moreira MD, PhD, and Professor Falcão de Freitas, MD, PhD

\section{References}

1.United States National Aeronautics and Space Administration. Scientific and Technical Information Division and Scarborough, William R., and United States Federal Aviation Agency. Ballistocardiography: a bibliography: a compilation of references to papers, reports, monographs, reviews, and books, of both domestic and foreign origin, which appeared during the period 18771964 [For sale by the Superintendent of Documents, U.S. Govt. Print. Off.], Washington: 1965

2.Pinto-Ferreira E. Ballistocardiographics Aspects in Mitral Stenosis. Dissertation of licentiateship submitted to Faculty of Medicine, Oporto University, 1964.

3.Jack Hirsh, Gordon Guyatt, Gregory W. Albers, et all. Antithrombotic and Thrombolytic Therapy: American College of Chest Physicians (ACCP) Evidence-Based Clinical Practice Guidelines. 8th Ed, Chest 2008;133:71S-105S.

4.Isaac Newton. The Mathematical Principles of Natural Philosophy. Third edition translated into Português by Andrew Motte. Middle-Temple-Gate, 1729 .

5 .Ernst Mach. The Science of Mechanics. The Open Court Publishing Company, 1915.

6.Steven C, Frautschi, Richard P. Olenick, Tom M. Apostol \& David L. Goodstein. The Mechanical Universe, Mechanics and Heat, Advance Edition. Cambridge University Press, 1986.

7.Rajani Thiranagama, Chamberlain AT, Professor. Wood BA. Valves in superficial veins limbs of humans and nonhuman primates. Clinical Anatomy. 2005; 2:135-145.

8.Phillips MN, Jones GT, van Rij AM, and Zhang M. Micro-venous valves in the superficial veins of the human lower limb. Clinical Anatomy. 2004;17:55-60.

9.Anatoly A. Gashev. Physiologic Aspects of Lymphatic contractile Function. Annals of the New York Academy Sciences. 2002;979:178-187

10.Guex JJ, Michel Perrin. Edema and Leg Volume: Methods of Assessement. Angiology. 2000;51:912.

11.Anick Berard, Xavier Kurz, François Zucarelli and Lucien Abenhain. Validity of Leg-O-Meter, an Instrument to Measure Leg Circuference. Angiology. 2002; 53: 21-28.

12.te Slaa å, Mulder P, Dolmans D, Castenmiller P, G HO and van der Laon L. Reliability and reproducibility of a clinical application of a simple technique for repeated circumferencial leg measurements. Phlebology. 2011;26:14-19.

13.Fedor Lurie, Robert L. Kistner, Bo Eklof, and Darcy Kessler. Mechanism of venous valve closure and role of the valve in circulation: A new concept. J. Vasc. Surg. 2003;38:955-61.

14.Juan J. Figueroa, Jeffrey R. Basford, Phillip A Low. Preventing and treating orthostatic hypotension: As easy as A, B, C. Cleve Clin J Med. 2010 May;77(5):298-306.

15.David Czell, Reinhard Schreier, Rüdiger Rupp, Rüdiger Rupp, Stephen Eberhard et all. Influence of passive leg movements on blood circulation on tilt table in healthy agults. J. Neuroengineering Rehabil. 2004;1:4.

16.Stick C, Jaeger H and Witzleb E. Measurements of volume changes and venous pressure in the human lower leg during walking and running. J. Appl. Physiol. June 1992; vol 72 no.6: 2063-2068. 
17.Hadia Shbaklo and Susan R. Kahn. Long-term prognosis after deep venous thrombosis. Current Opinion in Hematology. 2008;15;494-498.

18.Goats. G. J. Massage-the scientific basis of an ancient art: Part 1. The techniques. Br. J. Sports Med. 1994;28:149-152.

19.Goats G. J. Massage-the scientific basis of an ancient art: Part 2. Physiological and therapeutic effects. Br. J. Sports Med. 1994;28:153-156.

20.John Sitzia, Lydia Sobrido, Wendy Harlow. Manual Lymphatic Drainage Compared with Simple Lymphatic Drainage in the Treatment of Post-mastectomy Lymphoedema. A pilot randomised trial. Physiotherapy. 2002; 88:99-107. 